\title{
Study of electromagnetic field radiation on the human muscle activity
}

\author{
Mohd Shuhaibul Fadly Mansor*, Wan Abu Bakar Bin Wan Abas, Wan Nor Liza Binti Wan Mahadi
}

\begin{abstract}
The use of electrical appliances has enhanced the quality of life. As a result, the electricity demand rapidly increased. Although it provides advantages to life, people are exposed to the electromagnetic field radiation without realizing it. This study focuses on the impact of electromagnetic field radiation on the human muscles by using Electromyography (EMG) apparatus. The radiation is measured from the electrical appliances inside the office room with fluorescent lights as well as a computer with liquid crystal display (LCD) and cathode ray tube (CRT) screen. 17 subjects with no history of chronic musculoskeletal or abdominal pain participated in this study. The EMGs of the forearm muscles, including flexor carpi radialis (FCR), extensor carpi radialis longus (ECRL), flexor carpi ulnaris (FCU), and extensor carpi ulnaris (ECU) are recorded with a sampling rate of $2,000 \mathrm{~Hz}$. The analysis of variance (ANOVA) is performed to determine the impact of electromagnetic field radiation on the forearm muscles. It is found that CRT radiation has a significant effect on the forearm muscles.
\end{abstract}

Keywords Electromagnetic radiation, Electrical appliances, Muscle, Electromiography.

\section{Estudo da radiação de campo eletromagnético na atividade muscular humana}

Resumo O uso de aparelhos elétricos tem melhorado a qualidade de vida de todos. Como resultado, a demanda por energia elétrica aumentou rapidamente em todo o mundo. Contudo, apesar de oferecer muitas vantagens para a vida das pessoas, estas são expostas à radiação de campo eletromagnético sem perceber. Este estudo avalia os impactos da radiação de campo eletromagnético sobre a musculatura humana por meio da eletromiografia (EMG). A radiação emitida por equipamentos elétricos diversos no interior de um escritório, bem como por lâmpadas fuorescentes, monitores de computador a cristal líquido (LCD) e tubos de raios catódicos (CRT) foi medida e avaliada. 17 individuos sem história de dor músculo-esquelética ou abdominal crônica participaram deste estudo. Os eletromiogramas dos músculos do antebraço, incluindo flexor radial do carpo, extensor radial longo do carpo, flexor ulnar do carpo e extensor ulnar do carpo foram gravados a uma taxa de amostragem de $2 \mathrm{kHz}$. A análise de variância (ANOVA) foi realizada para determinar o impacto da radiação do campo eletromagnético sobre os músculos do antebraço. Os resultados demonstram que a radiação CRT tem um efeito significativo sobre os músculos do antebraço.

Palavras-chave Radiação eletromagnética, Aparelhos elétricos, Músculo, Eletromiografia. 


\section{Introduction}

\section{Electromagnetic fields}

Electromagnetism is the study of the effects of electric charges at rest and in motion. The electric fields (E-fields) are produced by stationary charges, positive or negative charges that exert a force on other charged objects in the field and are measured in volts per metre (V/m) (Cheng, 1989). Magnetic fields are produced by the motion of electric charges, which exert force on other moving charges. The magnetic field intensities are measured in amperes per metre $(\mathrm{A} / \mathrm{m})$. The magnitude of the magnetic field per unit area is known as the magnetic flux density and is measured in Tesla (T). The combination of these electric and magnetic fields results in the electromagnetic field (Habash, 2001).

\section{EMG}

Surface EMG measurement is an experimental technique for recording and quantifying the action potential along the skeletal muscle fiber's surface (De Luca, 1997; Farina et al., 2004). The action potential is generated during voluntary muscle action. The surface EMG is a compound signal produced by the electrical activities of many motor units (Basmajian and De Luca, 1985).

EMG provides many useful information and applications. It is generally beneficial in various uses in the field of biomechanics and physiological study. Besides, it is also playing a major role as an evaluation tool in medical research, sport training, rehabilitation, and ergonomics. In the application of ergonomics, it helps to enhance the risk prevention, analysis of demand, and ergonomic design. Moreover, EMG allows detecting the muscle activity, analyzing, and then improving the ergonomics design. In the sport science, EMG helps in analyzing and improves the sport activities (Konrad, 2005). Currently, the common applications of EMG signal are as following:

- Measurement of force produced by a particular muscle;

- Determining the activation timing of muscle, that is, when the excitation of muscle begins and ends;

- The use of EMG signals as a fatigue index;

- Estimation of how active is the muscle.

The specification of EMG measurement can be divided into a few parameters, including sampling rate, factors influencing EMG signal, and maximal voluntary isometric contraction.

\section{Sampling rate}

The process of signal digitization is defined by the concept of sampling rate. Thus, sampling frequency plays a critical role in establishing the accuracy of the sampled EMG signal in analog to digital conversion (De Luca, 2001). In this research the Myomonitor ${ }^{\circledR}$ IV EMG system (Delsys Inc.) was used. The bandwidth of the surface EMG is distributed at the range of $20 \pm 5 \mathrm{~Hz}$ to $450 \pm 50 \mathrm{~Hz}$; that is, the highest bandwidth of surface EMG is $500 \mathrm{~Hz}$.

\section{Factors influencing EMG signal}

There are several external factors that may influence and alter the characteristics and shape of the EMG signal. However, the effects of some of the factors may be managed by a proper detection method when using the EMG system efficiently in the experiment. Basically, they can be grouped into several categories, such as external electrical noise, anatomical and physiological crosstalk, geometry between muscle belly and electrode placement (Konrad, 2005).

Tissue characteristic influences the EMG signal. Although human body is a good electrical conductor, the electrical conductivity greatly varies with the thickness of tissue. Any increase in thickness can cause a decrease in the amplitude of EMG signal. In order to minimize the effect of tissue thickness in this research, it is suggested to limit the specific criteria of subject, i.e. the Body Mass Index (BMI) of the subject should be in the range of 18 to 24.5.

Another factor the influences EMG signal is physiological cross talk. It refers to a significant amount of EMG which originates from neighboring muscles but detected at local electrode site. Cross talk is generally defined as a signal that does not exceed $10-15 \%$ of overall signal (Konrad, 2005).

Electrical noise may originate from various sources such as inherent noise of the electronics components in the detection and recording equipments. All electronic equipments generate electrical noises that have frequency ranging from 0 up to several thousands of hertz. They cannot be eliminated but can be reduced by using high quality electronic components.

On the other hand, surface EMG electrode placement greatly influences the EMG signal. Muscle is typically located between a motor point and a tendon insertion, or within two motor points (Konrad, 2005). The longitudinal axis of the electrode (surface electrode with 2 parallel bars) should be placed at the middle of muscle belly, aligned to the length of the muscle fibers.

Tendinuos zone has fewer and thinner distribution of muscle fibers, resulting in reduction in the amplitude 
of the EMG signal. Besides, physical dimension of tendinous zone causes difficulty to locate surface electrode above it. Innervations zone is a motor point region, with high density of motor end plate. It is not recommended for electrode placement due to increasing EMG signal instability. At the point of motor region, the positive and negative phases of action potential cause a higher frequency to be detected in EMG signal (De Luca, 2002). Both regions of innervations zone and tendinous zone are not good locations to place electrodes.

Reference electrode is a neutral electrode needed to be placed for every subject when recording the EMG signal so as to provide a common reference to the differential input of amplifier in electrode. It is typically positioned at a place which is electrically unaffected but nearby to the measured area, such as joint, bony area, frontal head, and tibia bone (De Luca, 2001; 2002; Konrad, 2005). In the experiment of this research, the measured area is the forearm muscle; it was decided to place a reference electrode at the joint of the arm of the right hand.

\section{Maximal voluntary isometric contraction (MVC)}

MVC is a method to normalize the recorded data. It is important to rescale the percentage of a reference value $(100 \%)$ in order to standardize for all the subjects in the study. Typically, it is performed with a very good fixation and contraction against a rigid resistance (Konrad, 2005).

To produce a maximal contraction, trained subject is required. Patient with injury logically cannot perform MVC test. This is because the maximal contraction produced would be different compared to normal subject. However, in this research, normal subject with no history of chronic musculoskeletal or abdominal pain is the only specific criteria. It is assumed that the maximal contraction force generated by the subject serves as a reference value.

\section{Human muscle selection}

Typing is a task that involves the activation of the forearm muscles and finger muscles. To investigate the muscular participation while typing, a previous study (van Galen et al., 2007) has chosen the muscle groups as follows. The three pairs of extensor and flexor muscle are selected due to their involvement in lifting and downward pressing motion of finger during typing. The first pair is flexor digitorum superficial and extensor digitorum muscles, which are involved in downward and upward movement for horizontal, forward, and backward for vertical. The second pair is flexor carpi radialis (FCR) and extensor carpi radialis longus (ECRL) muscles, which have the similar function but restricted to medial movement during typing. The third pair is flexor carpi ulnaris (FCU) and extensor carpi ulnaris (ECU) muscles which are mostly for laterally directed movement.

According to van Galen et al. (2007), it is suggested that the muscles being involved are the FCU and FCR shown in Figure 1, and ECU and ECRL shown in Figure 2.

Basically, FCU is an ulnar abductor when acting with ECU. Its symmetry with insertion of ECU into the base of the fifth metacarpal is maintained by the way of pisometacarpal ligament (McMinn, 1995). This pair of muscles is essential in typing for the laterally directed movements.

Apart from that, FCR originated from the medial epicondyle of the humerus. It assists in the stabilization of the wrist in the finger and thumb movements. ECRL originated from the lateral epicondyle of the humerus, inserted as a flattened tendon into the base of second carpal on dorsal aspect of the hand. It acts as an extensor and abductor of the wrist and midcarpal joints (McMinn, 1995). This pair of muscles is frequently involved in keyboard movement with medial direction (van Galen et al., 2007).

According to a previous finding (Dvorak, 1936), the left hand is chosen for the electrode placement

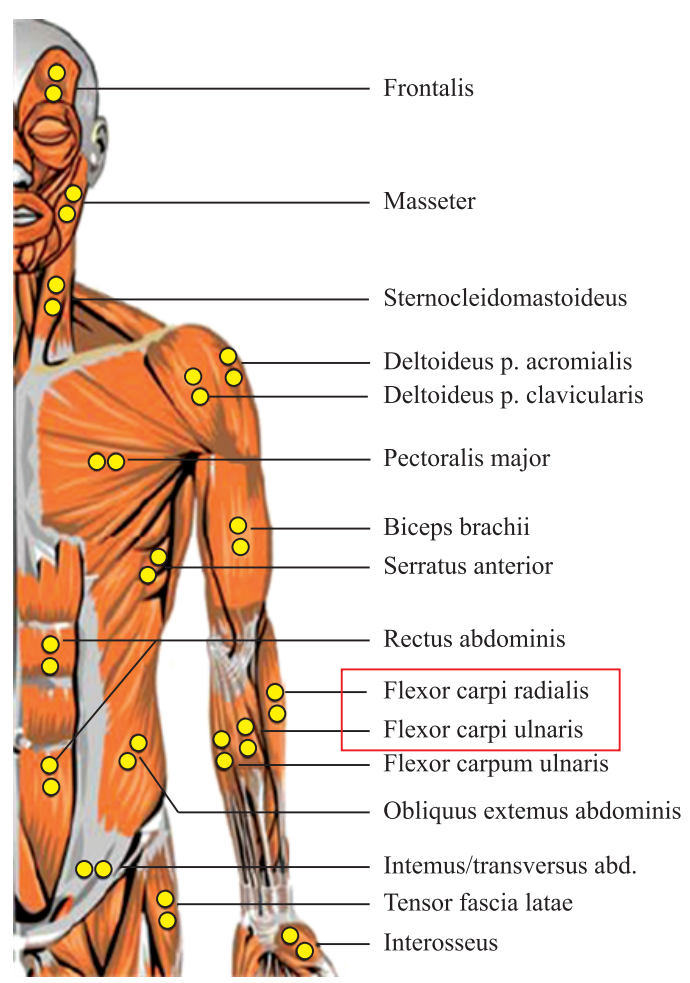

Figure 1. Location of surface muscle electrodes for FCR and FCU (Konrad, 2005). 


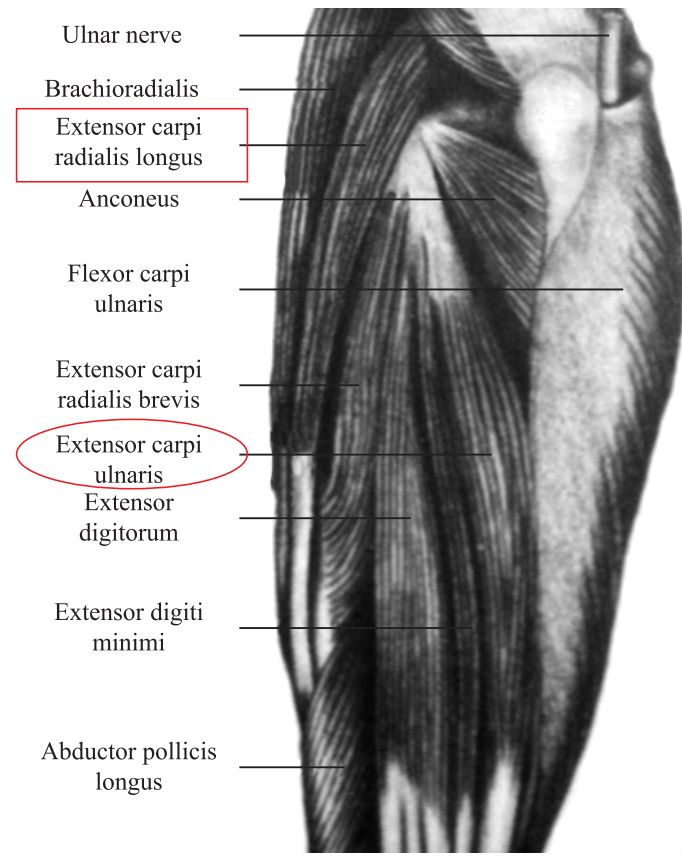

Figure 2. Location of ECU and ECRL (McMinn, 1995).

because it is responsible for $57 \%$ of all keystrokes on a QWERTY keyboard, which is the most common and modern keyboard layout on English language computers and typewriter keyboards. Therefore, in this research, it is decided to measure the muscle activity on left hand during typing where a conventional QWERTY keyboard is used.

\section{Signal processing}

EMG raw data is detected directly from EMG equipment without any processing. Raw data is normally contaminated with noise, thus digital filtering is necessary prior to the calculation of the root mean square (RMS) values. Inspection of the raw EMG is crucial to provide a good EMG baseline quality. The major factor is baseline offset, which is a phenomenon where EMG baseline shifted away from the true zero line. Baseline offset is indicated by the mean value of the raw data not equal to zero (Konrad, 2005).

Filter is a device designed to attenuate specific ranges of frequency, while allowing others to pass. Stopband is the range where the frequency is attenuated while band-pass is the range which is transmitted (De Luca, 2001). Generally, the transition range can be characterized by the order of the filter. Butterworth filter is best used for its maximally flat response in the transmission, minimizing the band-pass ripple.

In the present research, the EMG data is digital filtered by using second order Butterworth band-pass filter. By referring to previous researches, a band-pass filter of 20-450 Hz passband and second order was applied (Fagarasanu et al., 2005; Szeto and Ng, 2000). Besides, high-pass filter of $20 \mathrm{~Hz}$ is used to eliminate low frequency artifacts such as movement during typing activity (Cook et al., 2004; Nag et al., 2009; Szeto et al., 2005).

The digital filtered EMG signal is processed to calculate the parameters desired for the purpose of this study. The parameter can be expressed in various aspects of muscle function, such as frequency, amplitude, and time domains. However, amplitude domain is focused in this research. Generally, amplitude provides information about the level of muscle activation, affected by the numbers of active motor units and the firing rates (De Luca, 1997). In more specific way, signal processing of amplitude domain comprises RMS, Moving Average (MovAvg), and Integration (IEMG).

In this research, the EMG signal is processed by calculation of RMS. It provides a more rigorous measure of information content of the EMG signal because it measures the energy of the signal (van Galen et al., 2007). It can be used to compare the EMG muscle activity for each case with different levels of electromagnetic field radiation and determine the most active muscle as well (Delsys, 2008). The RMS is used to assess the influence of arm and wrist support on the forearm during keyboard operation (Nag et al., 2009). Researches on wrist and shoulder muscle activity across computer task by using RMS (Dennerlein et al., 2002) have also been investigated. Apart from that, RMS is used to indicate the activity level of different task in the study of EMG measurement on neck-shoulder for computer workers (Kallenberga et al., 2006).

\section{Methods}

\section{Subjects}

17 healthy adults ( 10 males and 7 females) volunteered to participate in this experiment. The criteria are age between 19 to 30 years, no history of chronic musculoskeletal or abdominal pain, and BMI between 18 to $24.9 \mathrm{~kg} / \mathrm{m} 2$. The details of subjects are shown in Table 1. All subjects' muscles had enough rest (at least 30 minutes) before the measurement was taken. They were recommended not to expose themselves to any electromagnetic fields radiation/exposure before testing.

\section{Task}

The complete experiment in this study consisted of five keyboard typing sessions, in which the subjects 
Table 1. Details of subjects.

\begin{tabular}{lccccc}
\hline Subject & Gender & Age & $\begin{array}{c}\text { Height } \\
\text { (cm) }\end{array}$ & $\begin{array}{c}\text { Weight } \\
\text { (kg) }\end{array}$ & BMI \\
\hline Subject 1 & M & 24 & 170.0 & 62.0 & 21.5 \\
Subject 2 & M & 24 & 170.0 & 60.0 & 20.8 \\
Subject 3 & M & 24 & 167.0 & 58.0 & 20.8 \\
Subject 4 & M & 23 & 168.0 & 61.0 & 21.6 \\
Subject 5 & M & 23 & 176.5 & 65.0 & 20.9 \\
Subject 6 & M & 23 & 168.0 & 61.0 & 21.6 \\
Subject 7 & M & 23 & 176.0 & 63.5 & 20.5 \\
Subject 8 & M & 24 & 165.0 & 66.0 & 24.2 \\
Subject 9 & M & 24 & 186.0 & 79.0 & 22.8 \\
Subject 10 & M & 22 & 170.0 & 66.0 & 22.8 \\
Subject 11 & F & 22 & 153.0 & 47.0 & 20.1 \\
Subject 12 & F & 24 & 162.0 & 54.0 & 20.6 \\
Subject 13 & F & 24 & 168.0 & 61.0 & 21.6 \\
Subject 14 & F & 25 & 148.0 & 40.0 & 18.3 \\
Subject 15 & F & 24 & 167.0 & 58.0 & 20.8 \\
Subject 16 & F & 24 & 163.0 & 55.0 & 20.7 \\
Subject 17 & F & 24 & 158.0 & 50.0 & 20.0 \\
\hline
\end{tabular}

were exposed to the electromagnetic fields radiation of different levels. The amount of electromagnetic field exposure was measured by using EMDEX Snap. The electromagnetic fields radiation was increased in order to investigate and measure whether there was any difference in the muscle activity.

These five successive practice sessions of keyboard typing were separated by a short break, known as EMG baseline. About five minutes was given for the muscle to rest. EMG baseline is vital for references and comparison purposes. The measurement included the post measurement so as to make sure that the muscle was at its original condition after the electromagnetic fields were taken off. Before the experiment, Maximal Voluntary Isometric Contraction (MVCs) was performed in order to normalize the recorded data.

\section{Materials}

\section{EMG system}

The forearm muscle activity was measured using IV EMG system (Myomonitor ${ }^{\circledR}$, Delsys Inc.). It is an ultra-portable EMG data acquisition system which offers full-bandwidth signal recordings. It has dual mode operation which is either a wireless transmitter or an autonomous datalogger. Myomonitor ${ }^{\circledR}$ wireless is used in this experiment where the data is transmitted to a host computer nearby for storage and real-time viewing (Delsys, 2008).

\section{Computer}

Two types of computer monitors were involved, a cathode ray tube (CRT) and a liquid crystal display (LCD) monitors, as shown in Figures 3 and 4, respectively.

\section{Keyboard and test paragraph}

A conventional keyboard with English language QWERTY layout was used in the experiment. Test paragraph was a text prepared with 12 size Times New Roman font, and 1.5 line spacing.

\section{Procedures}

The experimenter explained all the procedures of the task performed to the subjects before every testing. The methodology flow chart is shown in Figure 5. The subjects sat on the adjustable office chair, allowing them to sit comfortably with their feet placed either on a footrest or on the floor. They were instructed to type for 30 seconds prior to the measurement of first trial to ensure all the signals registered correctly
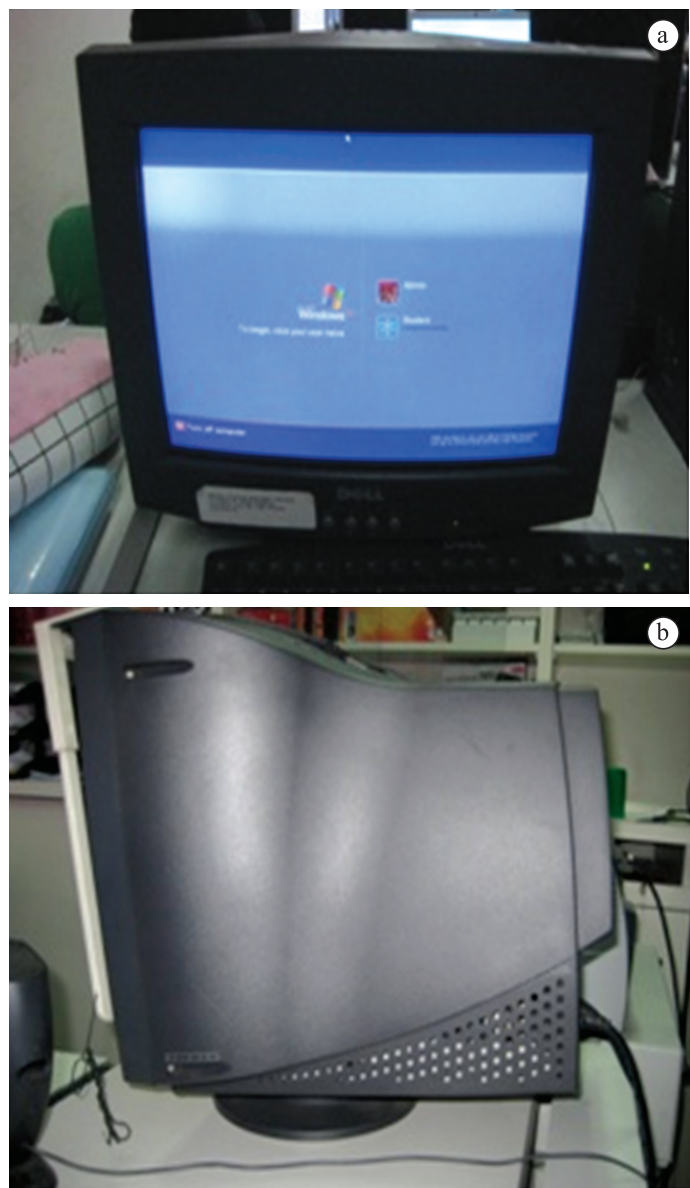

Figure 3. a) Front view and b) side view of CRT monitor. 


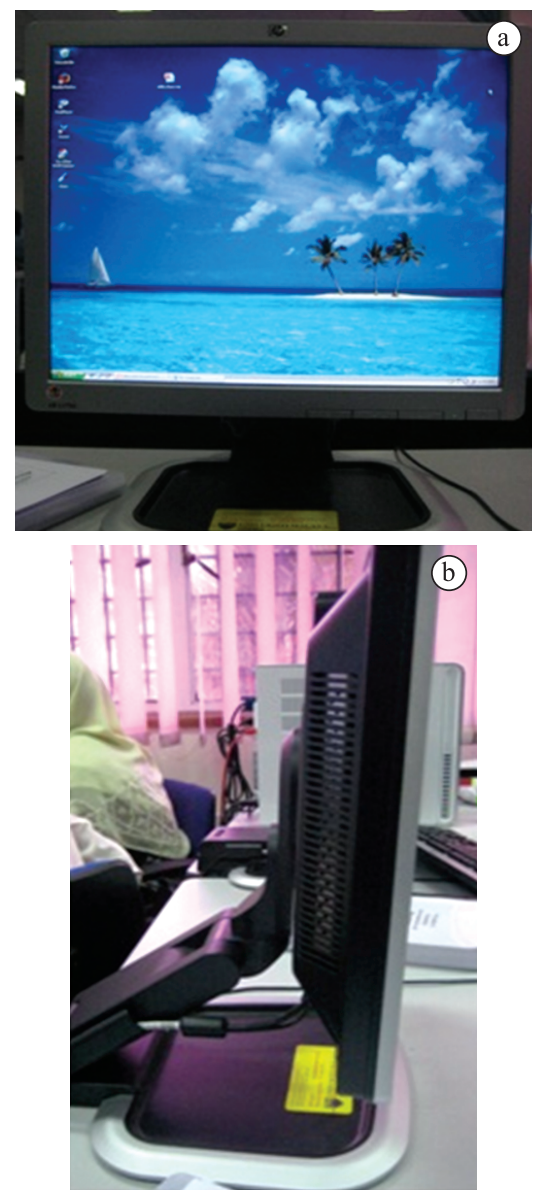

Figure 4. a) Front view, and b) side view of LCD monitor.

(van Galen et al., 2007). The subjects were instructed to type at their optimal speed, a given text paragraph, in order to standardize the muscle activation of measured forearm muscle.

\section{Exposure}

Five trials which involved typing performance had exposure to the electromagnetic field radiation at five different levels, as described below:

- CASE 1: Without any radiation (all electrical equipments in the room were turned off) control group;

- CASE 2: Exposure to 1 LCD display;

- CASE 3: Exposure to 1 LCD display and 4 fluorescent lights;

- CASE 4: Exposure to 1 CRT screen;

- CASE 5: Exposure to 1 CRT screen and 4 fluorescent lights.

The subjects were required to sit in a laboratory with predetermined exposure. They were instructed to perform typing task under particular electromagnetic

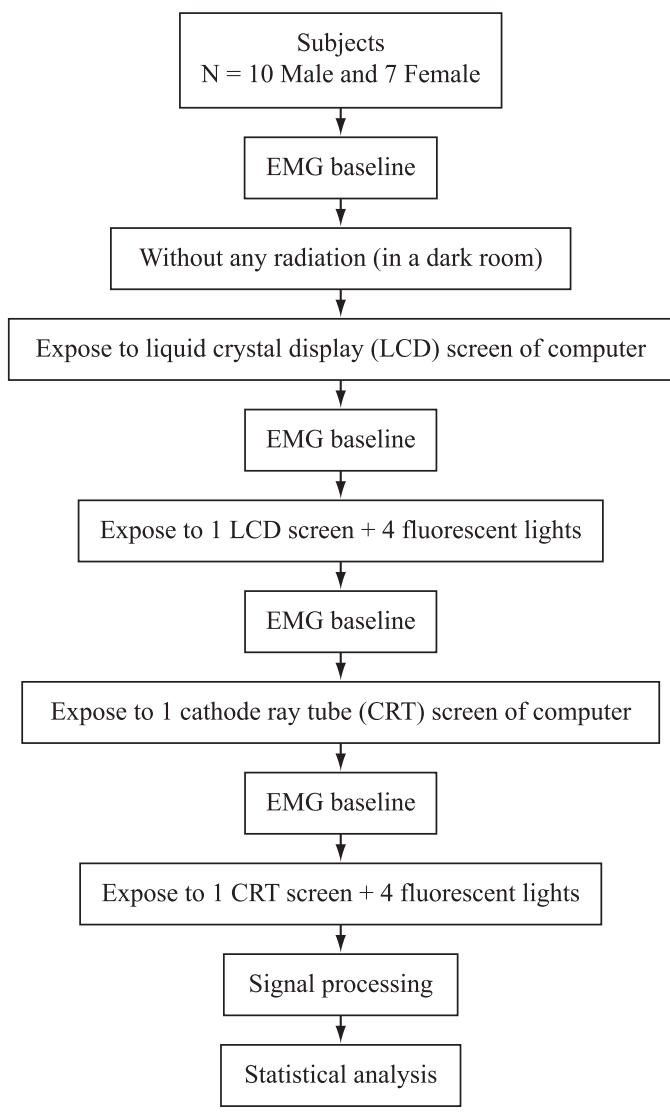

Figure 5. Flow chart of methodology for typing experiment.

fields radiation for 20 minutes (Lin et al., 1996). During the trial, the muscle activities were measured and recorded for 20 minutes. These procedures were repeated for five different levels of electromagnetic fields radiation as mentioned above.

\section{EMG baseline}

EMG baseline was measured each time before the subject was exposed to the electromagnetic field. Basically, there were five sessions of EMG baseline in the complete experiment. EMG baseline was measured for the forearm muscles in the subject sat in a room without any electromagnetic field exposure. This was achieved with all the fluorescent lights turned off and an electromagnetic field protection placed in front of the computer display. This reduced the amount of electromagnetic field exposure. The subjects were instructed to relax for 5 minutes and not make any movement for 30 seconds prior to the EMG baseline measurement. After that, the typing task was performed and the muscle activities were measured and recorded for 20 minutes. These procedures were repeated each time before a subject is exposed to the electromagnetic field radiation. 


\section{Surface electrode placement}

During the measurement sessions, the subjects were connected to the EMG apparatus. Firstly, the forearm surface was conditioned to improve the adhesion of the electrodes, especially under the humid condition or for sweaty skin types and/or dynamic movement conditions. It was followed by cleaning the skin (Konrad, 2005). There was no gel or skin preparation needed. The surface electrodes were placed parallel to the fibers of the muscle belly of relevant muscle at the left hand, with the reference electrode placed on the joint of right arm where the noise level was the lowest.

\section{EMG measurement}

The four concerned muscles of the upper extremity in the study are FCU, ECU, FCR, and ECRL. The first pair was FCU with ECU and second pair muscle was FCR with ECRL. They were chosen for being highly involved in keyboard typing activity. The first pair is essential for the laterally directed movements while the second pair is frequently involved in movement with medial direction on the keyboard (van Galen et al., 2007).

Prior to the measurement, the surface electrodes were placed respectively over the skin of the muscle under study. For the ECU, it was placed on the shaft of ulna in the middle of forearm, and for FCU it was about 2-3 cm volar to ulna at the junction of the upper and middle thirds of the forearm. For FCR, the electrode was placed 5-7 cm distal to the line connecting the medial epicondyles and biceps tendon (Fagarasanu et al., 2005). To measure ECRL, the surface electrode was recommended to be placed onto the lateral/dorsal aspect of the forearm (Delsys, 2008).

\section{Maximal voluntary contraction normalization}

A series of MVCs were collected for each muscle. The subjects were asked to hold their shoulder in a position of $90^{\circ}$ abduction and performed certain exercise to obtain MVC of each muscle with their maximum effort. The subjects were asked to hold in full extension and adduction of the wrist for ECU. Besides, the wrist was held in full extension for ECRL, full flexion and adduction of wrist for FCU, and again full flexion and abduction of the wrist for FCR (McMinn, 1995).

\section{Signal processing}

There were five cases in this experiment. The whole EMG data were recorded for each case with 20 minutes typing task. The EMG data were measured for 10 seconds period for each two minutes interval (Szeto and Ng, 2000). EMG data were analyzed by using EMGworks ${ }^{\circledR} 3.5$ software provided by Delsys Inc. There were few steps involved, including remove mean, digital filtering, subset (cut into segment with desirable duration), and compute RMS values.

\section{Statistical analysis}

The normalized RMS data were further analyzed by using SPSS version 16.0 to evaluate the difference of muscle activity between the five cases, where the level of electromagnetic field radiation increased from case two to case five. Normality is critical in statistical analyses. Basically, there are two types of testing normality, including graphical method and numerical method, such as P-P plots, Q-Q plots, and Kolmogorov-Smirnov test (Lilliefors test). Graphical method is easier to interpret while numerical method provides objective ways of examining normality (Park, 2008). Kolmogorov-Smirnov test was performed for statistical analysis of this research.

Univariate Analysis of Variances Test (ANOVA) or parametric test was performed if the variables follow the normal distribution. An additional post-hoc analysis was performed by using Tukey's HSD test. This is a multiple comparison test to test the hypothesis that all possible pairs of means are equal. A significant $F$ ratio indicates that there are differences between at least one pair of means (Kuzma and Stephen, 2005). In this research, the dependent variable was muscle and cases. An alpha level of 0.05 was selected. To test the hypothesis, these assumptions were made:

- The observations are independent; that is, normalized RMS value of one observation is not correlated with another value;

- The observations are normally distributed;

- The variance of various group are homogenous, that is, the variance of each case is equal to that of any other case.

Additionally, it was assumed that there was no significant difference between the subjects in terms of gender so as to ensure statistical similarity between the tested groups. The conclusion would be reject null hypothesis and accept alternative hypothesis if the probability value ( $p$-value) was found to be less than 0.05 .

\section{Results}

\section{Electromagnetic field measurement on electrical appliances}

The measurement is concentrated on the strength of electromagnetic field radiation/exposure from the electrical appliances, namely fluorescent lights and computer display. This strength of electromagnetic field 
for each LCD and CRT are shown in Figures 6 and 7, respectively.

The magnitude of electromagnetic field for five different cases during the experiment is summarized in Table 2.

\section{EMG measurement and statistical analysis}

\section{Data distribution}

In the statistical analysis, Kolmogorov-Smirnov test was selected. Table 3 indicated the test was normal distribution, implying that the variable followed a normal probability distribution because the alpha level was found to be less than 0.05 . Hence, parametric test was determined.

\section{ANOVA test}

Due to normal distribution of the data, ANOVA was selected to evaluate whether there was any significant difference of normalized RMS value between the cases. Additionally, post-hoc testing was performed using Tukey's method for multiple comparisons. The dependent variable was muscle and the factor was cases of exposure. An alpha level of 0.05 was selected. The null hypothesis and alternative hypothesis has been determined.

Null hypothesis, $\mathrm{H}_{\mathrm{o}}=$ There is a significant difference among the cases.

Alternative hypothesis, $\mathrm{H}_{1}=$ There is no significant difference among the cases.

\section{Pattern of muscle activities during typing}

The EMG data was examined throughout the typing task to look for any pattern of change during 20 minutes period for the five cases. Case 1 acted as control group, where the condition was without any electromagnetic field radiation. The level of electromagnetic field radiation increased from case 2 to case 5 .

From Figure 8 it is observed that the muscle activities fluctuated during the typing task for all cases

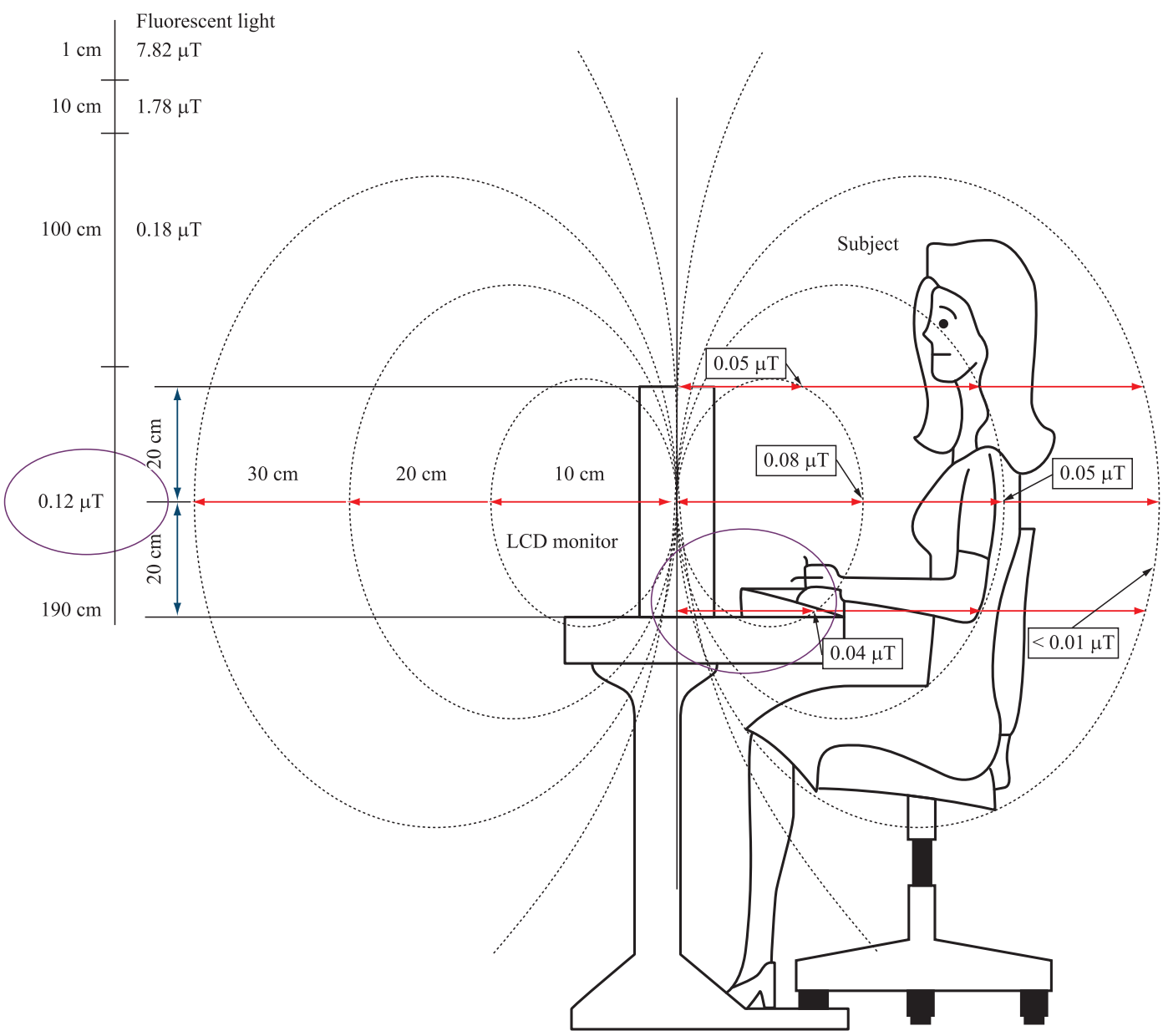

Figure 6. LCD monitor and fluorescent light. 


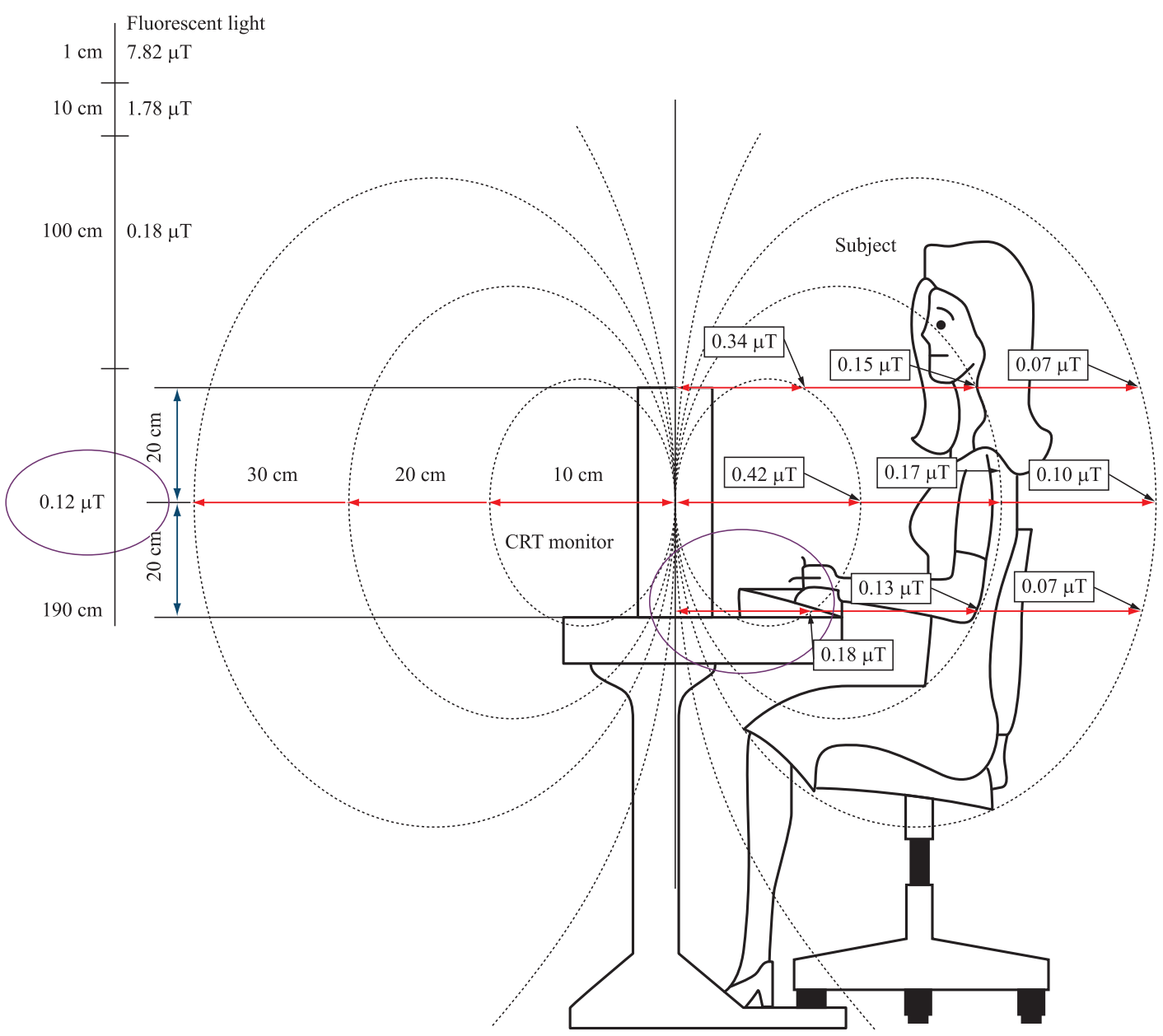

Figure 7. CRT monitor and fluorescent light.

Table 2. Electromagnetic fields measurement from EMDEX snap with different cases of exposure.

\begin{tabular}{lc}
\hline \multicolumn{1}{c}{ Cases } & $\begin{array}{c}\text { Electromagnetic fields } \\
\text { measurement from } \\
\text { EMDEX Snap }(\boldsymbol{\mu T})\end{array}$ \\
\hline $\begin{array}{l}\text { Case 1: Without any } \\
\text { electromagnetic field } \\
\text { exposure }\end{array}$ & 0.00 \\
$\begin{array}{l}\text { Case 2: Turn on computer } \\
\text { with LCD only }\end{array}$ & 0.04 \\
$\begin{array}{l}\text { Case 3: Turn on computer } \\
\text { with LCD and 4 } \\
\text { fluorescent lights }\end{array}$ & 0.16 \\
$\begin{array}{l}\text { Case 4: Turn on computer } \\
\text { with CRT only }\end{array}$ & \\
Case 5: Turn on \\
computer with CRT and 4 \\
fluorescent lights
\end{tabular}

in the four muscles. There were some inconsistent differences observed between the five cases. Both case 2 and case 3 showed no clear difference from control group. However, the difference between the control group with the case 4 and case 5 showed an obvious trend of reduction in normalized RMS value.

Figure 9 shows total fluctuation in the muscle activity of ECRL in every case. There was not any consistency among these 5 cases. However, both case 4 and case 5 were observed have values lower than the control group but with inconsistent difference.

From Figure 10, the muscle activities of ECU showed a random fluctuation in all cases as well. Case 2 and case 4 appeared to fluctuate more randomly than the others. No consistent difference could be found among the cases.

From Figure 11, FCU muscle appears more consistent compared to FCR, ECRL and ECU muscles. It was observed that the curve of the first three 
Table 3. One-sample Kolmogorov-Smirnov Test.

\begin{tabular}{|c|c|c|c|c|c|}
\hline & & FCR & ECRL & ECU & FCU \\
\hline \multicolumn{2}{|c|}{$\mathrm{N}$} & 850 & 850 & 850 & 850 \\
\hline \multirow{2}{*}{$\begin{array}{l}\text { Normal } \\
\text { parameters }^{\mathrm{a}}\end{array}$} & Mean & 8.8803 & 19.2839 & 18.7708 & 8.5728 \\
\hline & Std. deviation & 3.455 & 5.33516 & 5.85684 & 3.93538 \\
\hline \multirow{3}{*}{$\begin{array}{l}\text { Most extreme } \\
\text { differences }\end{array}$} & Absolute & 0.069 & 0.072 & 0.03 & 0.113 \\
\hline & Positive & 0.069 & 0.072 & 0.03 & 0.113 \\
\hline & Negative & -0.037 & -0.047 & -0.015 & -0.051 \\
\hline \multicolumn{2}{|c|}{ Kolmogorov-Smirnov Z } & 2.014 & 2.101 & 0.889 & 3.289 \\
\hline \multicolumn{2}{|c|}{ Asymp. Sig. (2-tailed) } & 0.001 & 0 & 0.408 & 0 \\
\hline
\end{tabular}

${ }^{\text {a }}$ Test distribution is normal.

FCR: Graph of normalized RMS values vs time
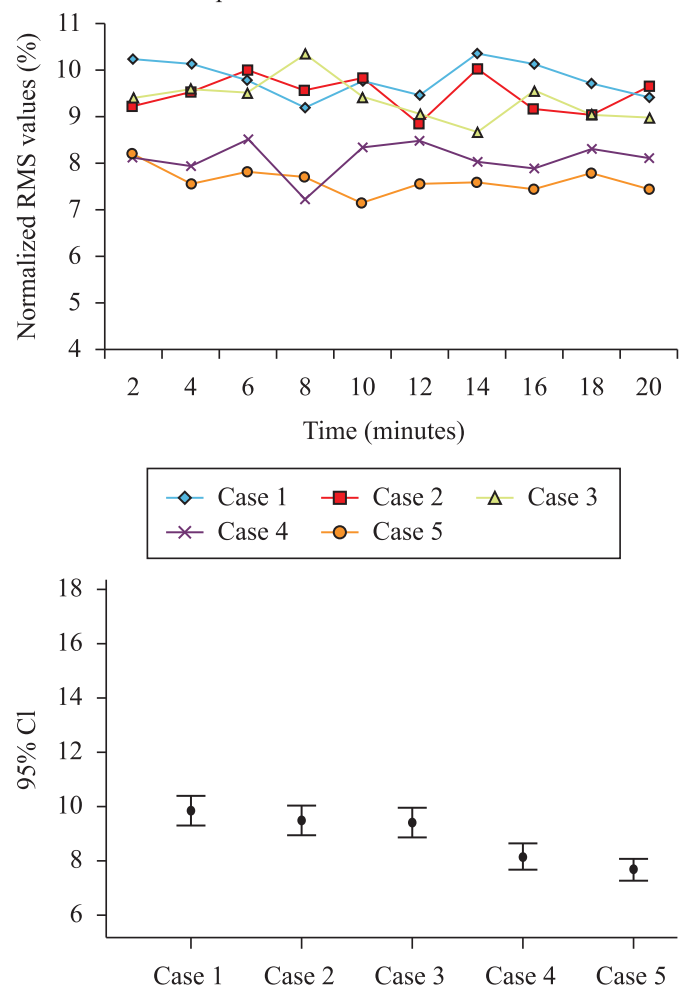

Figure 8. Graph of normalized RMS values vs time for FCR with standard deviation.

cases exhibited an obvious trend but an inconsistent difference still appeared among cases. It was noticed that the fluctuation often appeared in case 4 and case 5 .

By inspection on the line graph above in Figures 8-11, the pattern of muscle activities during typing can clearly be seen. However, there was no clear trend to prove any consistent difference between the cases. Thus, ANOVA was tested with $\alpha=0.05$ and the result is shown in Table 4.

Overall, Table 4 indicates that there were significant differences between the cases in the muscles of FCR, ECRL and FCU with $p=0.000, p=0.015$ and
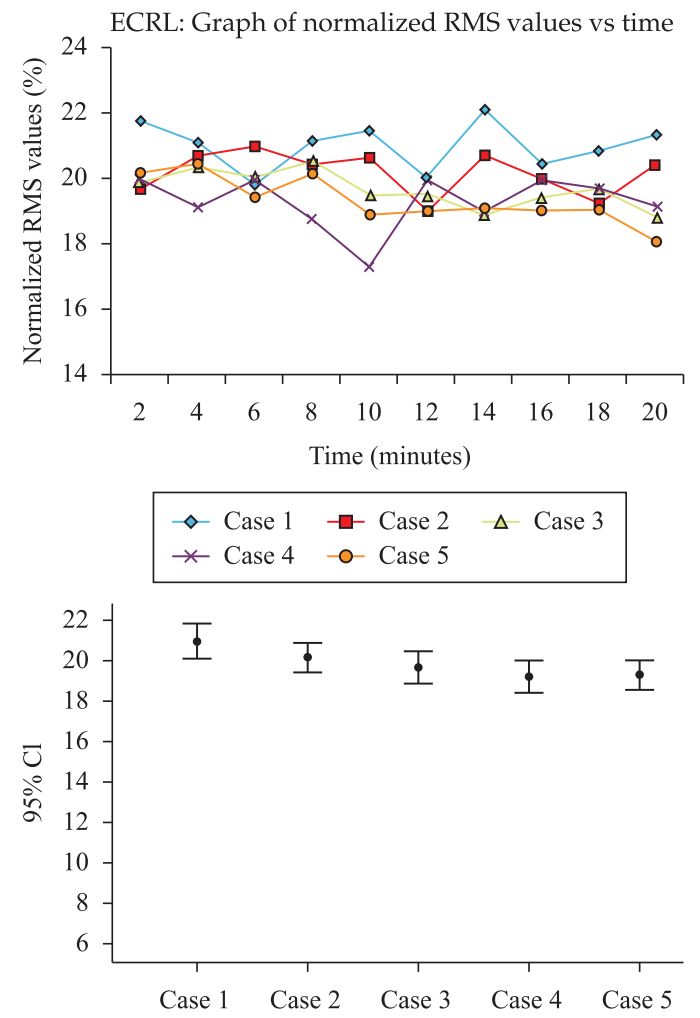

Figure 9. Graph of normalized RMS values vs time for ECRL with standard deviation.

$\mathrm{p}=0.000$ respectively. However, the EMG data of ECU had no statistical significant difference between the cases, with $\mathrm{p}=0.268$.

\section{Comparison of muscle activities between cases}

Although the present results demonstrated an overall significant difference between the cases in three muscles, it was of interest to investigate whether increase or reduction of the muscle activities varied with cases. Means and variance (SD) measures of all four muscles are summarized in the Table 5. In addition, Figure 12 shows the bar graph of mean of RMS values for each of the 5 cases of exposure level. 

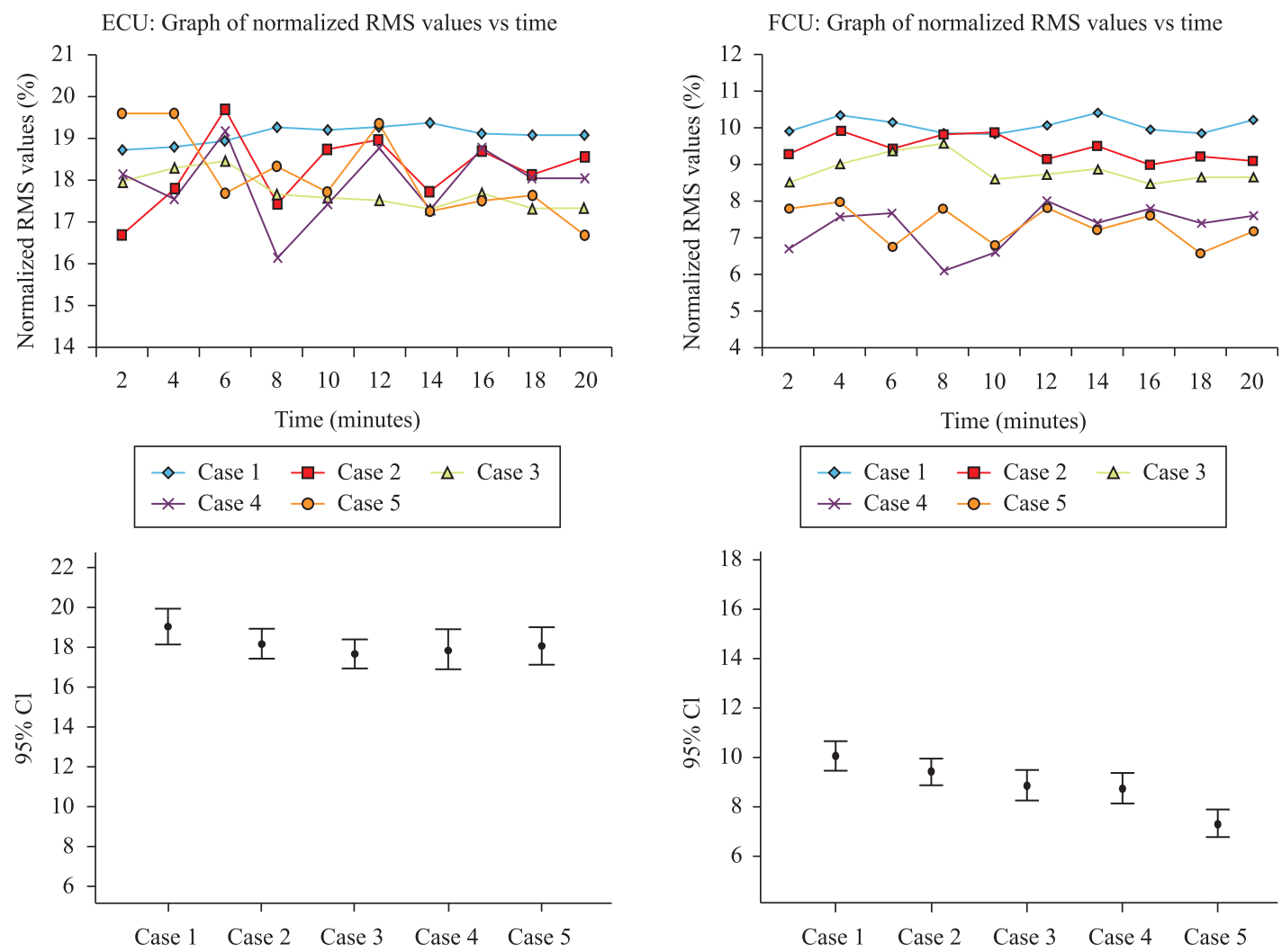

Figure 10. Graph of normalized RMS values vs time for ECU with standard deviation.

On the whole, it was obvious that the normalized RMS values of the extensor muscles were higher compared to flexor muscles. This means that the extensor muscle involves more muscular force when compared to the flexor muscles during typing. Case 1, which served as control, have the highest mean of normalized RMS values in every muscle. Generally, each muscle exhibited a reduction in normalized RMS values for every case, from case 2 to case 5, except for ECRL and ECU in case 5. They showed a slight increase of 0.60 for ECRL and 0.19 for ECU respectively in normalized RMS values compared to the previous cases.

However, the mean of normalized RMS values in Figure 12 do not provide a clear relationship in terms of statistical significant difference when compared to the control group. Therefore, statistical post-hoc multiple comparison test was performed.

\section{Comparison of cases to the control group}

In order to observe in depth which cases were significantly different from the control group, post-hoc test was performed using Tukey's method with $\alpha=0.05$. The multiple comparisons of case 1 to the

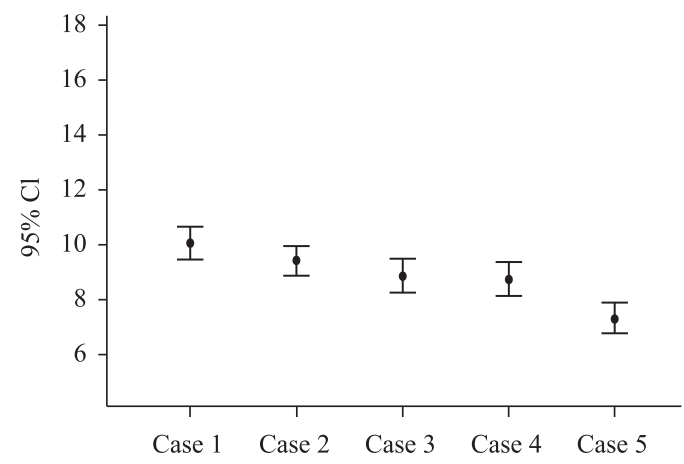

Figure 11. Graph of normalized RMS values vs time for FCU with standard deviation.

Table 4. Summary of ANOVA test with $\alpha=0.05$.

\begin{tabular}{|c|c|c|c|}
\hline Muscle & F-statistics & $p$ value & Conclusion \\
\hline FCR & 13.859 & 0.000 & $\begin{array}{l}\text { Significant difference } \\
\text { between cases }\end{array}$ \\
\hline ECRL & 3.117 & 0.015 & $\begin{array}{l}\text { Significant difference } \\
\text { between cases }\end{array}$ \\
\hline ECU & 1.301 & 0.268 & $\begin{array}{l}\text { No significant difference } \\
\text { between cases }\end{array}$ \\
\hline FCU & 18.773 & 0.000 & $\begin{array}{l}\text { Significant difference } \\
\text { between cases }\end{array}$ \\
\hline
\end{tabular}

other cases (case 2 to case 5) were made. The post-hoc result is summarized in Table 6 for all cases.

Both null and alternative hypotheses were made as below:

- Null hypothesis, Ho: $\mu 1=\mu 2=\mu 3=\mu 4=$ $\mu 5=\mu \mathrm{k}$, where $\mathrm{k}=$ number of cases;

- Alternative hypothesis, H1: at least one pair of sample means is different.

$\mathrm{p} \leq 0.05$ indicates that there is a significant difference. From Table 6, the ECU demonstrated no significant difference for all cases compared to the control group. Asides from that, for the muscles of FCR, ECRL, and FCU, it was generally observed 
Table 5. Mean and SD of normalized RMS values.

\begin{tabular}{crrrrr}
\hline Muscles & \multicolumn{5}{c}{ Cases (mean \pm SD) } \\
\cline { 2 - 6 } & \multicolumn{1}{c}{$\mathbf{1}$} & \multicolumn{1}{c}{$\mathbf{2}$} & \multicolumn{1}{c}{$\mathbf{3}$} & \multicolumn{1}{c}{$\mathbf{5}$} \\
\hline FCR & $9.82 \pm 3.39$ & $9.48 \pm 3.73$ & $9.38 \pm 3.68$ & $8.10 \pm 3.18$ & $7.63 \pm 2.68$ \\
ECRL & $20.38 \pm 5.64$ & $19.63 \pm 4.89$ & $18.97 \pm 5.23$ & $18.68 \pm 5.52$ & $19.28 \pm 5.34$ \\
ECU & $19.66 \pm 6.13$ & $18.67 \pm 5.16$ & $18.40 \pm 5.22$ & $18.47 \pm 6.43$ & $18.66 \pm 6.20$ \\
FCU & $10.06 \pm 4.03$ & $9.40 \pm 3.64$ & $8.85 \pm 4.01$ & $7.25 \pm 3.63$ & $7.31 \pm 3.57$ \\
\hline
\end{tabular}

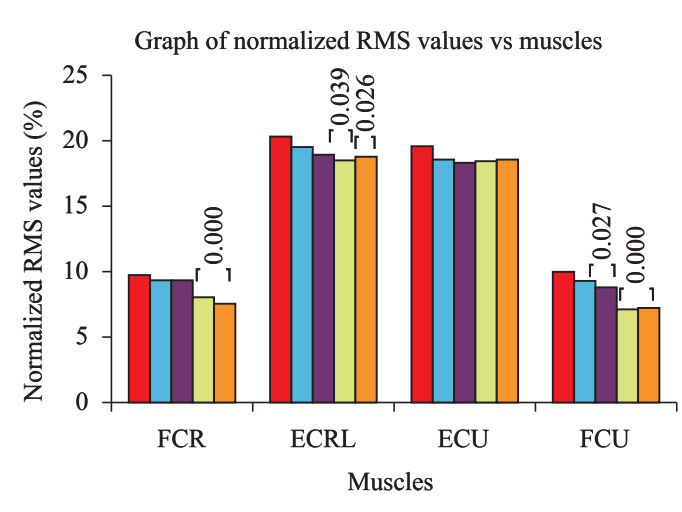

$\square$ Case $1 \square$ Case $2 \square$ Case $3 \quad \square$ Case $4 \quad \square$ Case 5

Figure 12. Graph of normalized RMS values vs Muscles.

that muscle activities for both case 2 and case 3 with exposure to LCD display radiation and addition of fluorescent lights to the exposure, reported no significant difference compared to the control group (except case 3 for FCU). However, both case 4 and case 5 , involving exposure of the forearm muscles to CRT screen radiation and addition to fluorescent lights, exhibited a significant difference when compared to the control group.

\section{Discussion}

\section{Pattern of muscle activities during typing}

When the normalized RMS values of five cases of exposure for the four muscles were plotted, it is observed that muscle activation level for all cases appeared to be inconsistent. This is because the normalized RMS values of extensor muscles were higher compared to flexor muscles. There was a frequent fluctuation observed throughout the whole 20 minutes recording period. This revealed that an inconsistent pattern is observed throughout the typing activity.

Research of Takala and Viikari-Juntura (1991) reported that muscle activities could be strongly influenced by small changes of upper arm angle. During typing, some subjects were found to change their elbow to a more comfortable sitting position. This also might lead to fluctuation of EMG signal.

\section{Comparison of muscle activities among cases}

In this research, the mean EMG data of normalized RMS values of flexor muscle and extensor muscle ranged from $7.25 \%$ to $10.06 \%$ and $18.40 \%$ to $20.38 \%$ respectively. This finding was consistent with those data obtained by Dennerlein et al. (2002) with average ranging from $8 \%$ to $25 \%$ in typing task. Another finding reported that by using standard QWERTY keyboard, mean of extensor muscles ranged from $8.1 \%$ to $10.5 \%$ (Szeto and Ng, 2000). Compared to this, the result of this research was somewhat higher. Indeed, it was difficult to compare the actual data between studies due to variation of experiment protocol and variation of individual subjects.

The typing posture while using conventional keyboard requires arm abduction and wrist extension so as to fit the keyboard design (Werner et al., 1997). Furthermore, in order to maintain or stabilize the static wrist posture during typing, extensor muscles have to put extra muscular effort (Andrew et al., 2002; McMinn, 1995; Szeto and Ng, 2000). This explains why extensor muscles have higher muscle activity compared to flexor muscles. However, the activation degree varied across different types of extensor muscle, with ECRL and ECU ranging from $18.63 \%$ to $20.38 \%$ and $18.40 \%$ to $19.66 \%$, respectively.

For the four muscles, the statistical results indicated that there was a significant difference among the cases only for the three investigated muscles, namely FCR, ECRL, and FCU. However, ECU was excluded; it did not show statistical significance between the cases.

\section{Comparison of cases to the control group}

By investigating the relationship of various cases to the control group, it was found that both case 2 and 3 did not show significant difference. By referring to Table 3, this means that exposure of $\operatorname{LCD}(0.04 \mu \mathrm{T})$ with addition of fluorescent lights exposure $(0.16 \mu \mathrm{T})$ did not give any significant impact on muscle activities for the all measured muscles while typing. The possible reason was that the radiation emitted from the LCD display was either not big enough to influence muscle 
Table 6. Summary of post-hoc (Tukey's HSD) within cases with $\alpha=0.05$.

\begin{tabular}{|c|c|c|c|c|c|c|}
\hline Muscle & Cases (I) & Cases $(\boldsymbol{J})$ & Mean difference (I-J) & P value & Decision & Conclusion \\
\hline \multirow[t]{4}{*}{ FCR } & Case 1 & Case 2 & 0.34012 & 0.883 & Do not reject $\mathrm{H}_{\mathrm{o}}$ & $\mu_{1}=\mu_{2}$ \\
\hline & & Case 3 & 0.44213 & 0.743 & Do not reject $\mathrm{H}_{\mathrm{o}}$ & $\mu_{1}=\mu_{3}$ \\
\hline & & Case 4 & $1.72317^{*}$ & 0.000 & Reject $\mathrm{H}_{\mathrm{o}}$ & $\mu_{1} \neq \mu_{4}$ \\
\hline & & Case 5 & $2.19126^{*}$ & 0.000 & Reject $\mathrm{H}_{\mathrm{o}}$ & $\mu_{1} \neq \mu_{5}$ \\
\hline \multirow[t]{4}{*}{ ECRL } & Case 1 & Case 2 & 0.75014 & 0.690 & Do not reject $\mathrm{H}_{\mathrm{o}}$ & $\mu_{1}=\mu_{2}$ \\
\hline & & Case 3 & 1.41037 & 0.103 & Do not reject $\mathrm{H}_{\mathrm{o}}$ & $\mu_{1}=\mu_{3}$ \\
\hline & & Case 4 & $1.70338 *$ & 0.026 & Reject $\mathrm{H}_{\mathrm{o}}$ & $\mu_{1} \neq \mu_{4}$ \\
\hline & & Case 5 & $1.62380 *$ & 0.039 & Reject $\mathrm{H}_{\mathrm{o}}$ & $\mu_{1} \neq \mu_{5}$ \\
\hline \multirow[t]{4}{*}{ ECU } & Case 1 & Case 2 & 0.98863 & 0.525 & Do not reject $\mathrm{H}_{\mathrm{o}}$ & $\mu_{1}=\mu_{2}$ \\
\hline & & Case 3 & 1.26459 & 0.271 & Do not reject $\mathrm{H}_{\mathrm{o}}$ & $\mu_{1}=\mu_{3}$ \\
\hline & & Case 4 & 1.19593 & 0.327 & Do not reject $\mathrm{H}_{\mathrm{o}}$ & $\mu_{1}=\mu_{4}$ \\
\hline & & Case 5 & 1.00223 & 0.511 & Do not reject $\mathrm{H}_{\mathrm{o}}$ & $\mu_{1}=\mu_{5}$ \\
\hline \multirow[t]{4}{*}{ FCU } & Case 1 & Case 2 & 0.65065 & 0.506 & Do not reject $\mathrm{H}_{\mathrm{o}}$ & $\mu_{1}=\mu_{2}$ \\
\hline & & Case 3 & $1.20794 *$ & 0.027 & Reject $\mathrm{H}_{\mathrm{o}}$ & $\mu_{1} \neq \mu_{3}$ \\
\hline & & Case 4 & $2.80734 *$ & 0.000 & Reject $\mathrm{H}_{\mathrm{o}}$ & $\mu_{1} \neq \mu_{4}$ \\
\hline & & Case 5 & $2.74425^{*}$ & 0.000 & Reject $\mathrm{H}_{\mathrm{o}}$ & $\mu_{1} \neq \mu_{5}$ \\
\hline
\end{tabular}

*The mean difference is significant at the 0.05 level.

activities or that the duration of exposure was short. This result could also be explained by physiological familiarization with LCD display of the subjects which commonly used it in their workplace.

Besides, the statistical result confirmed that the muscle activation was significantly lower for both cases of exposure to CRT radiation $(0.18 \mu \mathrm{T})$ with addition of fluorescent lights $(0.30 \mu \mathrm{T})$ compared to the control group. This revealed that the muscle activities were perhaps affected by the increase in radiation. It might explain that increasing radiation leads to lowering in muscle activity.

Skeletal muscle is responsible for muscle contraction while typing. The previous study by Pathak (2008) proved that there was temperature rise in skeletal muscle due to electromagnetic field radiation. This would cause additional stress in the body tissue. Furthermore, the study of Hannig and Lee (2000) reported that high energy radiation produced reactive oxygen intermediates (ROI) in tissue which could damage cell membrane through lipid peroxidation. Ionizing radiation was reported to primarily damage chemical structure in tissue. During first two hours of radiation, large blebs were formed on the surface of skeletal muscle cells and a sufficient amount of these blebs could contribute to cell death. Therefore, in this research, it was deduced that the electromagnetic field radiation caused additional stress in the forearm muscles and the generated large blebs on the surface of skeletal muscle might affect the functionality of muscle, thus, promoting a declination of forearm muscles activities after two hours of electromagnetic field exposure.

\section{Conclusion}

The effect of electromagnetic field radiation has been investigated. Measurement of EMG signals was done to reveal the muscle activities. An effect of electromagnetic field radiation was tested with different levels of radiation, by varying the exposure of LCD display, CRT screen, and fluorescent lights. It was found that CRT radiation produced a significant difference on the forearm muscles which cause declination in muscle activities but LCD display did not. Besides, the muscle activities of the extensor muscles were found to be higher than that of the flexor muscle while typing. In addition, the patterns of typing activity were observed.

\section{References}

Andrew W, Jeffrey DB, Parsons C. Neck shoulder and upper limb pain. In: Andrew W. Effective Management of Musculoskeletal Injury. 2002. 226 p.

Basmajian JV, De Luca CJ. Muscles Alive: their functions revealed by electromyography. 5 th ed. Baltimore: Williams and Wilkins; 1985.

Cook C, Burgess-Limerick R, Papalia S. The effect of upper extemity support on upper extremity posture and muscle activity suring keyboard use. Applied Ergonomics. 2004; 35(3):285-92. PMid:15145291. http://dx.doi.org/10.1016/j. apergo.2003.12.005

Cheng DK. Field and wave Electromagnetics. 2th ed. New York: Addison-Wesley; 1989.

De Luca CJ. Surface electromyography: detection and recording. In Delsys Inc.; 2002. Available in: http://www. delsys.com/Attachments_pdf/WP_SEMGintro.pdf 
De Luca CJ. The use of surface electromyography in biomechanics. Journal of Applied Biomechanics. 1997; 13(2):135-63.

De Luca G. Fundamental concepts in EMG signal acquisition. In Delsys Inc.; 2001. User's Guide. Available in: http:// www.delsys.com/Attachments_pdf/WP_Sampling1-4.pdf

Delsys. Myomonitor ${ }^{\mathbb{R}}$ IV EMG system. 2008. User's Guide. Available in: http://www.delsys.com/Attachments_pdf/ Myomonitor\%20IV\%20Users\%20Guide\%20(MAN-0022-0)-web.pdf

Dennerlein J, DiMarino MH, Becker T, Johnson P. Wrist and shoulder muscle activity change across computer tasks. In: HFES: Proceedings of the 46th HFES MUNUAL MEETING, 2002, Baltamore. Baltamore; 2002.

Dvorak A. Typewriting behaviour. New York: American Book Company; 1936.

Fagarasanu M, Kumar S, Narayan Y. The training effect on typing on two alternative keyboards. International Journal of Industrial Ergonomics. 2005; 35(6):509-16. http://dx.doi. org/10.1016/j.ergon.2004.12.001

Farina D, Merletti R, Enoka RM. The extraction of neural strategies from the surface EMG. Journal of Applied Physiology. 2004; 96(4):1486-95. PMid:15016793. http:// dx.doi.org/10.1152/japplphysiol.01070.2003

Habash RWY. Electromagnetic fields and radiation: human bioeffects and safety. New York: CRC; 2001.

Hannig J, Lee RC. Structural changes in cell membranes after ionizing electromagnetic field exposure. IEEE Transactions on Plasma Science. 2000; 28(1):97-101. http://dx.doi. org/10.1109/27.842873

Kallenberga LAC, Hermie JH, Vollenbroek-Huttena MMR. Distinction between computer workers with and witout work-related neck-shoulder complaints based on multiple surface EMG parameter. International Journal of Industrial Ergonomics. 2006; 36:921-929. http://dx.doi.org/10.1016/j. ergon.2006.07.005

Konrad P. The ABC of EMG: a practical introduction to kinesiological electromyography. Arizona: Noraxon Inc.; 2005. User manual.

Kuzma JW, Stephen EB. Basic statistics for the health sciences. 5th ed. New York: McGraw-Hill; 2005.
Lin H, Blank M, Jin M, Goodman R. Electromagnetic field stimulation of biosynthesis: Changes in c-myc transcript levels during continuous and intermittent exposures. Bioelectrochemistry and Bioenergetics. 1996; 39:215-20. http://dx.doi.org/10.1016/0302-4598(95)05040-X

McMinn RMH. Last's Anatomy Regional And Applied. 9th ed. Longman Singapore Publishers; 1995.

Nag PK, Pal S, Nag A, Nyas H. Influence of arm and wrist support on forearm and back muscle activity in computer keyboard operation. Applied Ergonomics. 2009; 40:286-91. PMid:18508029. http://dx.doi.org/10.1016/j. apergo.2008.04.016

Park HM. Univariate analysis and normality test using SAS, stata, and SPSS. Indiana University: the University Informatic Technology Services - UITS, Center for Statistical and Mathematical Computing; 2008. Technical working paper.

Pathak PP. Bio-thermal effects due to electromagnetic radiation. Chicago: URSI; 2008.

Szeto PY, Ng KF. A comparison of wrist posture and forearm muscle activities while using an alternative keyboard and a standard keyboard. Journal of Occupational Rehabilitation. 2000; 10(3):189-97. http://dx.doi. org/10.1023/A:1026662302131

Szeto PY, Stracker LM, O'sullivan PB. The effect of speed and force of keyboard operation on neck-shoulder muscle activities in symptomatic and asymptomatic office workers. International Journal of Industrial Ergonomics. 2005; 35:429-44. http://dx.doi.org/10.1016/j.ergon.2004.10.009

Takala EP, Viikari-Juntura EV. Loading of shoulder muscles in a simulated work cycle: comparison between sedentary workers with and without neck-shoulder symptoms. Clinical Biomechanics. 1991; 6:145-152. http://dx.doi. org/10.1016/0268-0033(91)90025-L

Van Galen, GP, Hanneka L, De Haan A. Effects of vertical keyboard design on typing performance, user comfort and muscle tension. Applied Ergonomics. 2007; 38:99-107. PMid:16516844. http://dx.doi.org/10.1016/j. apergo.2005.09.005

Werner R, Armstrong TJ, Bir C, Aylard MK. Intracarpal canal pressure: the role of finger, hand, wrist and forearm position. Clinical Biomechanics. 1997; 12:44-51. http:// dx.doi.org/10.1016/S0268-0033(96)00044-7

\section{Authors}

Mohd Shuhaibul Fadly Mansor, Wan Abu Bakar Bin Wan Abas

Department of Biomedical Engineering, Faculty of Engineering, University of Malaya, 50603, Kuala Lumpur, Malaysia 